\title{
Application of Pseudo-Symmetric technique for seismic analysis of concrete arch dams
}

\author{
O. Omidi \& V. Lotfi \\ Department of Civil and Environmental Engineering, \\ Amirkabir University of Technology, Iran
}

\begin{abstract}
Dam-reservoir interaction can be treated by different approaches. One of the efficient methods available for time domain analysis is referred to as PseudoSymmetric technique. In the present study, a gravity dam example is considered to verify this technique. Subsequently, water compressibility effects on seismic behaviour of a typical concrete arch dam are studied. It is found that by considering water compressibility the maximum tensile stresses mat increase significantly which may lead to more severe damage during an earthquake.

Keywords: concrete arch dams, water compressibility, coupled equations, Pseudo-Symmetric technique, wave equation, Lagrangion-Eulerian formulation.
\end{abstract}

\section{Introduction}

The earthquake analysis of concrete dams has been the subject of extensive studies during the last three decades because of the importance of their safety evaluation. The dam-reservoir interaction problem encountered in such an analysis is a complex task which is traditionally represented using the added mass approach. The added mass approximation may lead to significant error in response during an earthquake [1]. The dam-reservoir system is classified as a coupled field problem that two separate regions of fluid and structure interact only at their interface. In order to solve these coupled equations, several methods exist in both time and frequency domains. Although this problem is formulated very efficiently in frequency domain, it is limited to linear dynamic analysis $[2,3]$. Therefore, time domain methodology is mainly preferred due to the fact that it can be also employed for nonlinear analyses. 
In time domain, the finite element method is mainly utilized to discretize different regions. In Lagrangian-Eulerian formulation, which is often used, unsymmetrical matrices are obtained for total mass and stiffness of the coupled system. In this formulation, displacement and pressure degrees of freedom are taken into account for the elements of dam and reservoir, respectively. Direct or simultaneous solution and partitioned scheme are the two classes of the solutions for the coupled field systems $[4,5]$. The principal aim of this paper is to employ an efficient method for three-dimensional seismic analysis of concrete dams by the direct method in time domain which is referred to as the Pseudo-Symmetric technique. At first, theoretical background of the subject is reviewed and then the pseudo-symmetric approach is summarized [4]. The procedure is implemented in a special computer program (SNACS). This analysis tool is verified initially and afterwards, the earthquake evaluation of Shahid Rajaee concrete arch dam is considered as a numerical example and the obtained results are discussed.

\section{Reservoir mathematical model}

Assuming water to be an irrotational and inviscid fluid, the small amplitude motion of water is governed by the wave equation:

$$
\nabla^{2} p=\frac{1}{C^{2}} \frac{\partial^{2} p}{\partial t^{2}}
$$

where, $C$ is the velocity of pressure waves in water and $p$ is the hydrodynamic pressure in excess of the hydrostatic pressure. It is well known that under the assumption of incompressible fluid, $C$ approaches infinity and eqn (1) converts to the Laplace's equation.

In order to solve the above governing equation in the reservoir, the boundary conditions need to be imposed. For the dam-reservoir interface, the condition is:

$$
\frac{\partial p}{\partial n}=-\rho a_{n d}^{s}
$$

where, $n$ is the outward normal to the boundary and $a_{n d}^{s}$ is the normal acceleration of the dam at the interface. At the reservoir bottom or side-walls, an approximate boundary condition is employed:

$$
\frac{\partial p}{\partial n}=-\rho \mathrm{a}_{n r}^{\mathrm{g}}-q \frac{\partial p}{\partial t}
$$

where, $q$ is the admittance or damping coefficient for the corresponding boundary and $a_{n r}^{g}$ is the free field ground acceleration in the $n$-direction. 
The coefficient $q$ is also related to a more meaningful wave reflection coefficient $\alpha$ [3]:

$$
\alpha=\frac{1-q C}{1+q C}
$$

This is defined as the ratio of the amplitude of the reflected hydrodynamic pressure wave to the amplitude of a propagating pressure wave incident on the reservoir bottom or side-walls in the normal direction. This coefficient changes from zero to one and in the case of rigid foundation it is equal to one. A transmitting boundary is necessary for the far end of the reservoir and the Sommerfeld boundary condition is most often utilized for this purpose:

$$
\frac{\partial p}{\partial n}=-\frac{1}{C} \frac{\partial p}{\partial t}
$$

This results in a damping in the system and models the loss of energy in the outgoing waves. Its main assumption is that at long distance from the dam, pressure waves propagate as plane waves. For the free surface of the reservoir, zero pressure condition is usually applied (i.e., surface gravity waves are neglected).

\section{Coupled dam-reservoir equations}

The dynamic equilibrium equations of dam body are quite well known. Furthermore, applying Galerkin approach to the governing equation of the reservoir, and imposing the boundary conditions mentioned above, the coupled dam-reservoir equations can be written as the following in matrix notation [4]:

$$
\begin{gathered}
{\left[\begin{array}{cc}
{[\mathrm{M}]} & {[0]} \\
\rho[\mathrm{B}] & \mathrm{C}^{-2}[\mathrm{G}]
\end{array}\right]\left\{\begin{array}{l}
\{\ddot{\mathrm{r}}\} \\
\ddot{\mathrm{P}}\}
\end{array}\right\}+\left[\begin{array}{cc}
{[\mathrm{C}]} & {[0]} \\
{[0]} & {[\mathrm{L}]}
\end{array}\right]\left\{\begin{array}{l}
\{\dot{\mathrm{r}}\} \\
\{\dot{\mathrm{P}}\}
\end{array}\right\}} \\
+\left[\begin{array}{cc}
{[\mathrm{K}]} & -[\mathrm{B}]^{\mathrm{T}} \\
{[0]} & {[\mathrm{H}]}
\end{array}\right]\left\{\left\{\begin{array}{l}
\mathrm{r}\} \\
\{\mathrm{P}\}
\end{array}\right\}=\left\{\begin{array}{c}
-[\mathrm{M}][\mathrm{J}]\left\{\mathrm{a}_{\mathrm{g}}\right\} \\
-\rho[\mathrm{B}][\mathrm{J}]\left\{\mathrm{a}_{\mathrm{g}}\right\}
\end{array}\right\}\right.
\end{gathered}
$$

In relation $(6),[\mathrm{M}],[\mathrm{C}]$ and $[\mathrm{K}]$ symbolize the mass, damping and stiffness of the dam body, respectively. $\{\mathrm{r}\}$ is the vector of nodal relative displacements and $\left\{\mathrm{a}_{\mathrm{g}}\right\}$ represents the vector of ground accelerations. [J] is a matrix with each three rows equal to a $3 \times 3$ identity matrix (its columns correspond to unit rigid body motion in each three direction). The assembled matrices of fluid domain are represented as $[\mathrm{G}],[\mathrm{L}]$ and $[\mathrm{H}]$, respectively. 
There exist different techniques for the solution of such un-symmetric coupled equations. Direct or simultaneous solution based on un-symmetric solver is time consuming and inefficient, especially when large number of elements are used in the model. ANSYS program utilizes an un-symmetric solver to find the solution of these coupled equations by its acoustic media module [6].

Another option based on symmetric matrices to solve the equations is referred to as the partitioned solution. The staggered approach is a partitioned solution procedure based on an iterative scheme that separates dam and reservoir equations and solves them by sequential execution of a single domain analyzer. In this study, the third alternative is employed [4] which is summarized in the following.

\section{Pseudo-Symmetric technique}

The technique begins by modifying relation (6), such that the lower partition of this relation is multiplied by a factor of $-\left(\rho \mathrm{a}_{0}\right)^{-1}$ where, $\mathrm{a}_{0}$ is a coefficient employed in Newmark's algorithm. This yields

$$
\begin{aligned}
& {\left[\begin{array}{rr}
{[\mathrm{M}]} & {[0]} \\
\frac{-1}{\mathrm{a}_{0}}[\mathrm{~B}] & \frac{-1}{\rho \mathrm{a}_{0} \mathrm{C}^{2}}[\mathrm{G}]
\end{array}\right]\left\{\begin{array}{l}
\{\ddot{\mathrm{r}}\} \\
\{\ddot{\mathrm{P}}\}
\end{array}\right\}+\left[\begin{array}{cc}
{[\mathrm{C}]} & {[0]} \\
{[0]} & \frac{-1}{\rho \mathrm{a}_{0}}[\mathrm{~L}]
\end{array}\right]\left\{\begin{array}{c}
\{\dot{\mathrm{r}}\} \\
\{\dot{\mathrm{P}}\}
\end{array}\right\}} \\
& +\left[\begin{array}{cc}
{[\mathrm{K}]} & -[\mathrm{B}]^{\mathrm{T}} \\
{[0]} & \frac{-1}{\rho \mathrm{a}_{0}}[\mathrm{H}]
\end{array}\right]\left\{\begin{array}{l}
\{\mathrm{r}\} \\
\{\mathrm{P}\}
\end{array}\right\}=\left\{\begin{array}{l}
-[\mathrm{M}][\mathrm{J}]\left\{\mathrm{a}_{\mathrm{g}}\right\} \\
\frac{1}{\mathrm{a}_{0}}[\mathrm{~B}][\mathrm{J}]\left\{\mathrm{a}_{\mathrm{g}}\right\}
\end{array}\right\}
\end{aligned}
$$

Or alternatively, in a more compact form:

$$
[\overline{\mathrm{M}}]\{\ddot{\overline{\mathrm{r}}}\}+[\overline{\mathrm{C}}]\{\dot{\overline{\mathrm{r}}}\}+[\overline{\mathrm{K}}]\{\overline{\mathrm{r}}\}=\{\overline{\mathrm{R}}\}
$$

It is obvious that the matrices $[\overline{\mathrm{M}}],[\overline{\mathrm{C}}]$ and $[\overline{\mathrm{K}}]$ can be written as sum of symmetric and un-symmetric parts as below:

$$
\begin{gathered}
{[\overline{\mathrm{M}}]=\left[\mathrm{M}_{\mathrm{S}}\right]+\left[\mathrm{M}_{\mathrm{U}}\right]} \\
{[\overline{\mathrm{C}}]=\left[\mathrm{C}_{\mathrm{S}}\right]} \\
{[\overline{\mathrm{K}}]=\left[\mathrm{K}_{\mathrm{S}}\right]+\left[\mathrm{K}_{\mathrm{U}}\right]}
\end{gathered}
$$


It can be easily verified that the following relation also holds:

$$
\left[\mathrm{K}_{\mathrm{U}}\right]=\mathrm{a}_{0}\left[\mathrm{M}_{\mathrm{U}}\right]^{\mathrm{T}}
$$

Applying Newmark's algorithm on eqn (8) and employing relations $(9 \mathrm{a}-\mathrm{c})$, the effective stiffness matrix and the equivalent force vector at instant $n+1$ would be:

$$
\begin{gathered}
{[\hat{\mathrm{K}}]=\mathrm{a}_{0}\left(\left[\mathrm{M}_{\mathrm{S}}\right]+\left[\mathrm{M}_{\mathrm{U}}\right]\right)+\mathrm{a}_{1}\left[\mathrm{C}_{\mathrm{S}}\right]+\left(\left[\mathrm{K}_{\mathrm{S}}\right]+\left[\mathrm{K}_{\mathrm{U}}\right]\right)} \\
\left\{\hat{\mathrm{R}}_{\mathrm{n}+1}\right\}=\left\{\overline{\mathrm{R}}_{\mathrm{n}+1}\right\}+\left(\left[\mathrm{M}_{\mathrm{S}}\right]+\left[\mathrm{M}_{\mathrm{U}}\right]\right)\left(\mathrm{a}_{0}\left\{\overline{\mathrm{r}}_{\mathrm{n}}\right\}+\mathrm{a}_{2}\left\{\dot{\overline{\mathrm{r}}}_{\mathrm{n}}\right\}+\mathrm{a}_{3}\left\{\ddot{\bar{r}}_{\mathrm{n}}\right\}\right)+ \\
{\left[\mathrm{C}_{\mathrm{S}}\right]\left(\mathrm{a}_{1}\left\{\overline{\mathrm{r}}_{\mathrm{n}}\right\}+\mathrm{a}_{4}\left\{\dot{\overline{\mathrm{r}}}_{\mathrm{n}}\right\}+\mathrm{a}_{5}\left\{\ddot{\overline{\mathrm{r}}}_{\mathrm{n}}\right\}\right)}
\end{gathered}
$$

Finally, substituting relation (10) into (11), the rearranged effective stiffness matrix is concluded which is clearly symmetric:

$$
[\hat{\mathrm{K}}]=\mathrm{a}_{0}\left(\left[\mathrm{M}_{\mathrm{S}}\right]+\left[\mathrm{M}_{\mathrm{U}}\right]+\left[\mathrm{M}_{\mathrm{U}}\right]^{\mathrm{T}}\right)+\mathrm{a}_{1}\left[\mathrm{C}_{\mathrm{S}}\right]+\left[\mathrm{K}_{\mathrm{S}}\right]
$$

In this study, a computer program is developed (i.e., SNACS [7]) based on the above approach in an efficient symmetric, skyline storage allocation technique for all main matrices involved. Moreover, the symmetric active column procedure is employed for the solution routine [4].

In the following, after verifying the above mentioned tool, seismic response of a typical arch dam is discussed.

\section{Verification of the program}

For verification purposes, the earthquake response of Pine Flat dam is compared with ANSYS's results. It should be mentioned that in reference [4], the response of this dam has been also compared with the available results taken from the work of Chopra et al. The model specifications such as the geometry (fig. 1), material properties and the earthquake excitation are similar to this reference. However, in the present modeling, 8-node elements are used for both solid and fluid domains discretizations. The corresponding solid and fluid elements in ANSYS are referred to as SOLID45 and FLUID30, respectively.

As mentioned, ANSYS program employs the un-symmetric storage viewpoint for the matrices and it uses an un-symmetric solver. The assumptions utilized in the two programs to derive the coupled equations are alike; therefore one can expect exactly similar results as shown in fig. 2 . 


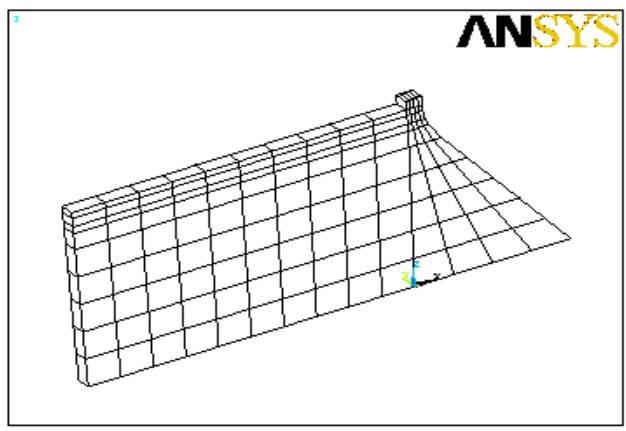

Figure 1: The mesh used for modeling of Pine Flat dam in ANSYS and SNACS.

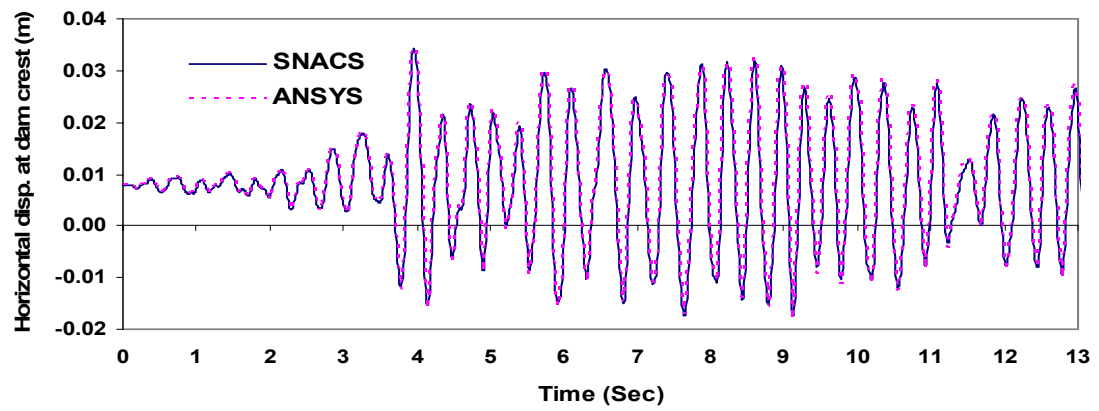

Figure 2: Time history of the dam crest displacement in stream direction (ANSYS vs. SNACS).

\section{Application on concrete arch dam}

In this section, the seismic response of Shahid Rajaee arch dam is studied as a typical concrete arch dam. The dam is $130 \mathrm{~m}$ high; with the crest length of $420 \mathrm{~m}$ and it is located in the north of Iran in the seismically active foothills of Alborz Mountains.

\subsection{Finite element idealization and basic specifications}

The idealized symmetric model of Shahid Rajaee concrete arch dam is considered here. The finite element mesh used for its dam body consists of 487 nodes and 76 isoparametric 20-node solid elements in two layers through the thickness of the dam. The whole model is illustrated in Fig. 3, which has 1179 nodes and 216 isoparametric 20 -node elements.

For static loading conditions, dead weight and hydrostatic pressures at upstream face are applied on monolithic dam body. The maximum water depth is considered as 122 meters. 


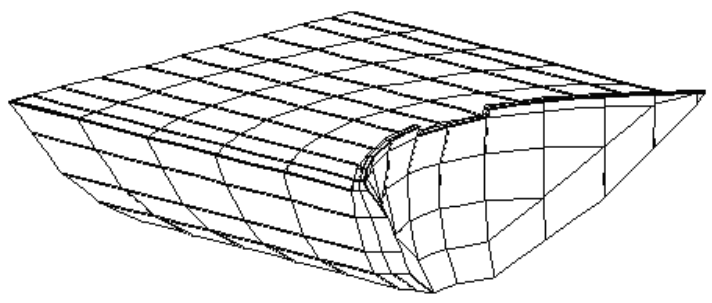

Figure 3: Idealized finite element discretization of Shahid Rajaee arch dam.

The earthquake excitations include two components of the Friuli-Tolmezzo earthquake (the cross-canyon is neglected to have a symmetric condition) whose records are normalized based on the frequency content for Maximum Design Earthquake (MDE) condition with the peak ground acceleration of $0.56 \mathrm{~g}$. The Rayleigh damping coefficients were determined such that the equivalent damping for frequencies close to the first and sixth modes of vibration would be $10 \%$ of the critical damping. The earthquake duration applied is 12 seconds, which covers the main response of the dam due to these excitations. The foundation is rigid and the far end truncated boundary of the reservoir is located at the distance of about 2 times the height of the dam. The concrete is assumed to be homogeneous and isotropic. The basic material properties are: $\mathrm{E}_{\mathrm{c}}=30.0 \mathrm{GPa}$, $v_{\mathrm{c}}=0.18, \gamma_{\mathrm{c}}=24.0 \mathrm{kN} / \mathrm{m}^{3}$.

\subsection{Selected models}

Two cases are considered. Since one of the main goals of the paper is to investigate the effects of water compressibility on the response, a case with the assumption of incompressible water theory needs to be also analyzed to make the comparison possible. Therefore, in Case A, the velocity of pressure waves approaches infinity. Case B is carried out with compressible water assumption $(\mathrm{C}=1440 \mathrm{~m} / \mathrm{s})$. In this case, the reflection coefficient of the reservoir bottom and side-walls is taken as 0.75 .

\subsection{Analysis results}

As mentioned above, two cases are analyzed. The time history of mid-crest displacements in the stream direction is compared between these cases in fig. 4 .

Furthermore, the maximum values of displacements at two key points of dam crest are summarized in table 1 . In this table, $\mathrm{U}, \mathrm{V}$ and $\mathrm{W}$ symbolize displacement components corresponding to cross-stream, downstream and vertical directions, respectively. It is apparent that maximum displacements obtained are slightly higher for the case of incompressible water. Although the maximum downstream value is increased in case A, maximum displacement toward upstream is somewhat more for the compressible case. It indicates that 
the seismic behavior has rather changed due to considerations of water compressibility and also reservoir bottom and side-walls absorption.

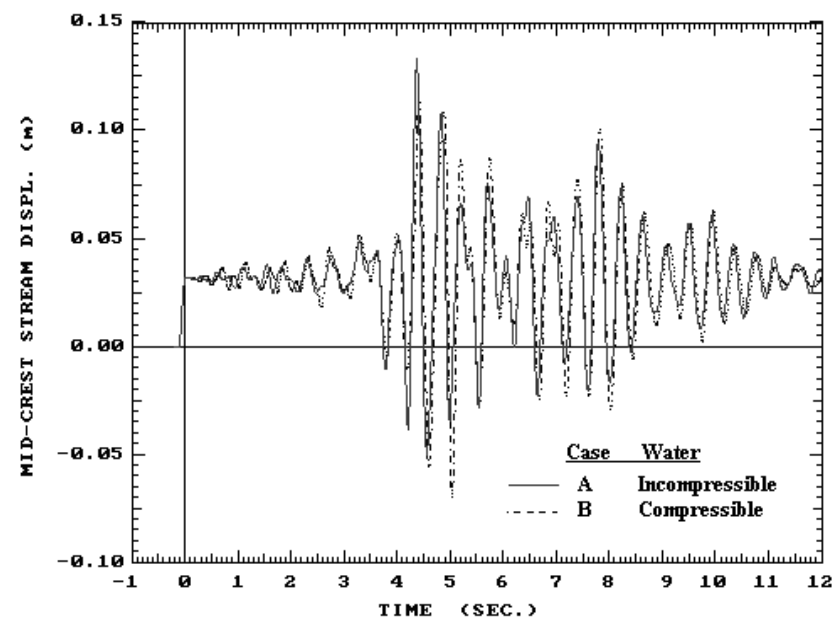

Figure 4: Comparison of displacements in the stream direction at mid-crest.

Table 1: $\quad$ Maximum displacements ( $\mathrm{mm})$ at dam crest.

\begin{tabular}{ccccccc}
\hline \multirow{2}{*}{ Case } & \multicolumn{2}{c}{ Center point } & & \multicolumn{3}{c}{ Right-quarter point } \\
\cline { 2 - 3 } \cline { 5 - 7 } & $\mathrm{V}$ & $\mathrm{W}$ & & $\mathrm{U}$ & $\mathrm{V}$ & $\mathrm{W}$ \\
\hline $\mathrm{A}$ & 133.5 & -7.3 & & -26.1 & 66.0 & 4.7 \\
\hline $\mathrm{B}$ & 113.5 & -10.1 & & -22.7 & 51.9 & 4.5 \\
\hline
\end{tabular}

In each case, the envelopes of maximum and minimum principal stresses throughout the time are obtained. The envelopes of maximum tensile and compressive principal stresses are illustrated in figs. 5-8. Furthermore, the maximum values in different regions are summarized in Table 2 . In the figures, left and right parts represent half of the model in downstream and upstream view, respectively.
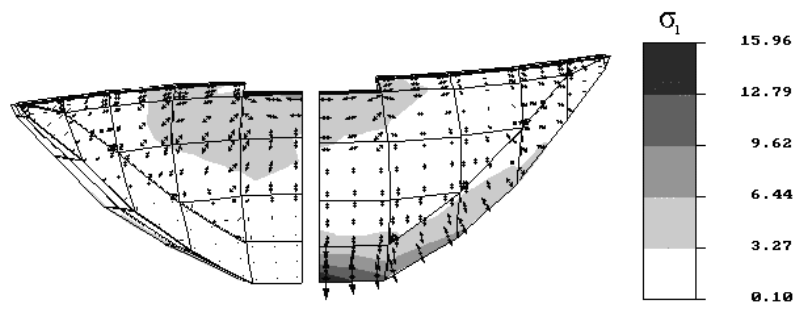

Figure 5: Envelope of maximum tensile stresses (MPa) for case A. 

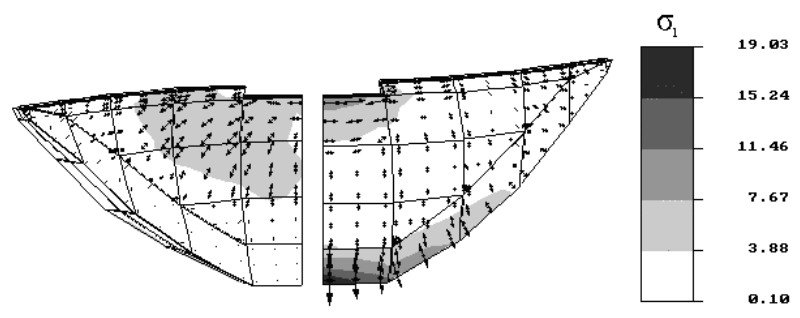

Figure 6: $\quad$ Envelope of maximum tensile stresses $(\mathrm{MPa})$ for case B.
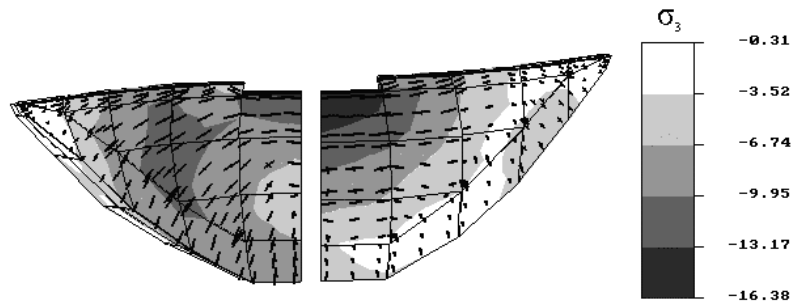

Figure 7: $\quad$ Envelope of maximum compressive stresses (MPa) for case A.
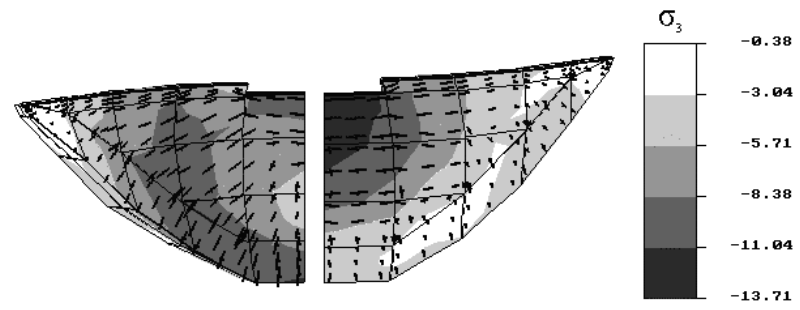

Figure 8: $\quad$ Envelope of maximum compressive stresses (MPa) for case B.

Table 2: $\quad$ Maximum and minimum principal stresses ( $\mathrm{MPa})$.

\begin{tabular}{cccccc}
\hline \multirow{2}{*}{ Case } & \multicolumn{2}{c}{ Max. $\sigma_{1}$} & & \multicolumn{2}{c}{ Min. $\sigma_{3}$} \\
\cline { 2 - 3 } \cline { 5 - 6 } & $\begin{array}{c}\text { Spillway \& } \\
\text { Middle portion }\end{array}$ & $\begin{array}{c}\text { Base \& } \\
\text { Abutments }\end{array}$ & & $\begin{array}{c}\text { Spillway \& } \\
\text { Middle portion }\end{array}$ & $\begin{array}{c}\text { Base \& } \\
\text { Abutments }\end{array}$ \\
\hline $\mathrm{A}$ & 7.32 & 15.96 & & -16.38 & -10.01 \\
\hline $\mathrm{B}$ & 9.60 & 19.03 & & -13.71 & -11.33 \\
\hline
\end{tabular}


The envelopes of maximum tensile stresses show an increase of about $31 \%$ and $19.2 \%$ in comparison with the incompressible water case occurring in the upstream face of the spillway and abutments regions, respectively. As expected, the maximum tensile principal stresses of these zones occur in the arch direction and perpendicular to the abutments. Regarding compressive stresses for case B, it is noted that maximum value on the upstream face of the spillway region is decreased, while the value on the abutments at downstream face is increased slightly in comparison with the incompressible water, case A.

\section{Conclusions}

In this study, additional examples for Pseudo-Symmetric approach are presented. The special program (SNACS) developed based on this methodology, is verified by ANSYS program. Subsequently, water compressibility effects on the earthquake behavior of an arch dam are investigated. With due attention to the importance of tensile stresses in arch dams, it was noted that by considering water compressibility the maximum tensile stress occurring at the upstream face may increase significantly in comparison with incompressible theory. It should be also mentioned that the technique implemented is very convenient and although the procedure was employed for linear dynamic analysis, it is easily expandable to nonlinear dynamic analysis of concrete dams, since it is carried out in time domain.

\section{References}

[1] Ghaemian, M. and Ghobarah, A., Nonlinear seismic response of concrete gravity dams with dam-reservoir interaction, Engineering Structures, 21, 306-316, 1999.

[2] Hall, J. F. and Chopra, A. K., Dynamic analysis of arch dams including hydrodynamic effects, Journal of Engineering Mechanics, ASCE, Vol. 109, No. 1, 149-167, 1983.

[3] Fok, K. L. and Chopra, A. K., Water compressibility in earthquake response of arch dams, Journal of Structural Engineering, ASCE, Vol. 113, No. 5, 958-975, 1987.

[4] Lotfi V., Seismic analysis of concrete dams by Pseudo-Symmetric technique, Journal of Dam Engineering, XIII, Issue 2, 2002.Mirzabozorg, H., Khaloo, A.R. and Ghaemian, M., Staggered solution scheme for three dimensional analysis of dam-reservoir interaction, Journal of Dam Engineering, XIV (III): 147-179, 2003.

[6] ANSYS, User's Manual, Revision 5.4, 1997.

[7] Omidi, O., "SNACS: A program for Seismic Nonlinear Analysis of Concrete Structures", Amirkabir University of Technology, Tehran, Iran, Fall 2006. 